\title{
A Rat Model for Monitoring Homograft Rejection of the Lung
}

\author{
Takashi Kondo, Fumihiro Shionozaki, Shigefumi \\ Fujimura, Atsushi Yamauchi, Masashi Handa, Takeshi \\ Okabe, Ryo Saito, Takashi Ichinose, Yuji Shiraishi \\ and Tasuku Nakada
}

Department of Surgery, the Research Institute for Tuberculosis and Cancer, Tohoku University, Sendai 980

\begin{abstract}
Kondo, T., Shionozaki, F., Fujimura, S., Yamauchi, A., Handa, M., Okabe, T., Saito, R., Ichinose, T., Shiraishi, Y. and Nakada, T. A Rat Model for Monitoring Homograft Rejection of the Lung. Tohoku J. exp. Med., 1986, 149 (3), 323-328 - A new surgical procedure was devised for the experimental homograft of the lung. The pulmonary artery and vein and bronchus were anastomosed under the operation microscope using interrupted sutures in group W (30 outbred Wistar rats) and continuous sutures in group F (7 inbred F344/Ducrj Rats). Mean ischemia time during the operation was $95.3 \pm 10.3 \mathrm{~min}$ in the group $\mathrm{W}$ and $55.6 \pm$ 5.8 in group F. Eight out of 30 rats $(27 \%)$ of group W and all rats of group F survived more than $24 \mathrm{hr}$ after the surgery. Pulmonary functions of grafted lungs were evaluated by serial $\mathrm{x}$-rays and the perfusion ratio was $27.4 \pm 11.6 \%$ (mean \pm S.D.) in group $\mathrm{W}$ and $25.4 \pm 7.7 \%$ in group F. A patent opening of the hilar anastomosis in these rats was confirmed at autopsy. This model with continuous suture would be useful for the rat lung transplantation. _— rat lung transplantation; microsurgery
\end{abstract}

Although recent improvement in the immunosuppressive therapy has promised successful transplantation of various organs, proper measures to monitor the onset of graft rejection are still in great demand. Particularly, in lung transplantation, differentiation of graft rejection from incidental infections is an urgent task since respiratory infections are apt to occur in immunosuppressed hosts. We describe a new rat model suitable for the study of lung transplantation.

\section{Materials and Method}

Left lung homotransplantation was carried out in 30 male Wistar rats weighing 160-250 $\mathrm{g}$ and in 7 male F344/Ducrj rats weighing 160-240 g. After intramuscular administration of atropine sulfate $(0.03 \mathrm{mg} / 100 \mathrm{~g}$ of body weight), recipient rats were intravenously given sodium pentobarbital $(5 \mathrm{mg} / 100 \mathrm{~g})$ and methylprednisolone $(0.5 \mathrm{mg} / 100 \mathrm{~g})$, and then

Received February 25, 1986 ; accepted for publication May 12, 1986.

Supported in part by a Grant-in-Aid for Scientific Research No. 752-5265-59480287 from the Ministry of Education, Science and Culture, Japan. 
intubated with a tefron tube (outer diameter of $1.1 \mathrm{~mm}$ and $6 \mathrm{~cm}$ long) under a surgical microscope (Konan K-880). The rats were sporadically inhalated with halothane with the aid of a Harvard rodent respirator (Model 680) operating with the tidal volume of 2-2.5 ml and respiration rate of $80-100 / \mathrm{min}$ under positive endoexpiratory pressure of $5 \mathrm{cmH}_{2} \mathrm{O}$. The chest cage was opened through the left 4 th intercostal space. The pulmonary ligament was dissected and hilar soft tissues were separated thoroughly. After placement of Hifetz's clamps, the bronchus, pulmonary artery and pulmonary vein were transected in this order. The bronchus and pulmonary artery were cut at the points just distal to the sites of clamping to secure the tissue for suturing. The pulmonary vein was separated at a cuff of the atrium.

After atropine administration and intubation, a thoracotomy was performed in donors through the 6th intercostal space. After intracardiac infusion of $100 \mathrm{u}$ of heparin and lmg of methylprednisolone, the pulmonary ligament was severed with a caution not to injure the left lung. The procedure for the isolation of the lung was similar to that for recipients. The pulmonary artery was first transected. The left atrium was clamped proximal to the opening of pulmonary veins, and separated leaving enough tissue for anastomosis. The lung was fully inflated and bronchus was occluded with a forceps prior to the isolation of the lung. Hilar stumps of the pulmonary artery and vein and bronchus attached to the left lung were trimmed again to secure the tissue appropriate for suturing. The lung was transplanted by anastomosis of the pulmonary vein, brounchus and pulmonary artery in this order. With a $10-0$ or 9-0 nylon thread, continuous suture was used in group F, and interrupted suture in group W (Fig. 1). Intrathoracic drain was indwelled until spontaneous respiration was sufficiently restored. Two milligrams of aminobenzylpenicillin was given i.m. on the 1st, 2nd and 3rd postoperative days.

Pulmonary functions of the transplants were periodically monitored by chest $\mathrm{x}$-rays (at least twice a week), and the perfusion lung scan with ${ }^{99 m}$ TC-MAA (macroaggregated albumin) was performed 24 to 49 days after grafting. Autopsy specimens were processed for histology.

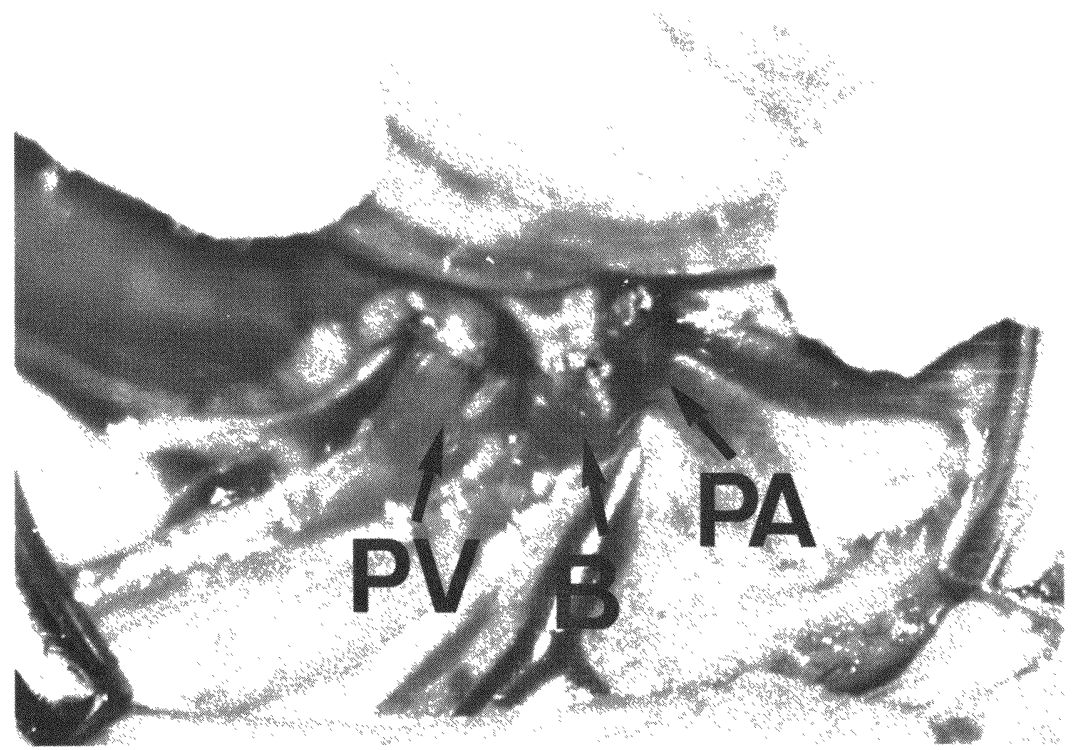

Fig. 1. A photograph taken during operation. The pulmonary vein (PV), bronchus (B) and pulmonary artery (PA) have been anastomosed. 


\section{RESULTS}

Out of 30 rats in group W, 8 rats $(27 \%)$ survived more than $24 \mathrm{hr}$ after grafting. Bleeding ( 15 rats), sputum retention (2 rats), pulmonary edema (4 rats) and accident (1 rat) were accounted for the death of 22 rats within $24 \mathrm{hr}$ after surgery. Among 8 survivals, 2 died of unknown cause and 2 of respiratory infections during the course of the experiment. In group $\mathrm{F}$, all rats survived the operation and only one was lost due to thrombosis of of the pulmonaly vein on the 7th postoperative day (Table 1). Operation time ranged from 146 to $220 \mathrm{~min}$ with the average of $177.2 \mathrm{~min}$ in group $\mathrm{W}$ and from 121 to $142 \mathrm{~min}$ (131.5 min on average) in group F. Mean ischemia time during grafting was 86.8 min in group $\mathrm{W}$ and $51.3 \mathrm{~min}$ in group $\mathrm{F}$. By 7 th postoperative day, satisfactory expansion and aeration of the grafted lungs was shown on chest $\mathrm{x}$-rays in all 15 survivals, although slight reimplantation response or insufficient reexpansion remained in a few instances (Table 2). Perfusion ratio of the left lung in five normal controls was $42.1 \pm 3.4 \%$. In group $\mathrm{W}$, the perfusion ratio of grafted lungs was $27.4 \pm$ $11.6 \%$ (16.8 to $45.1 \%, n=5)$, and $25.4 \pm 7.7 \%(17.8$ to $35.1 \%, n=5)$ in group $\mathrm{F}$ (Fig. 3 and Table 2).

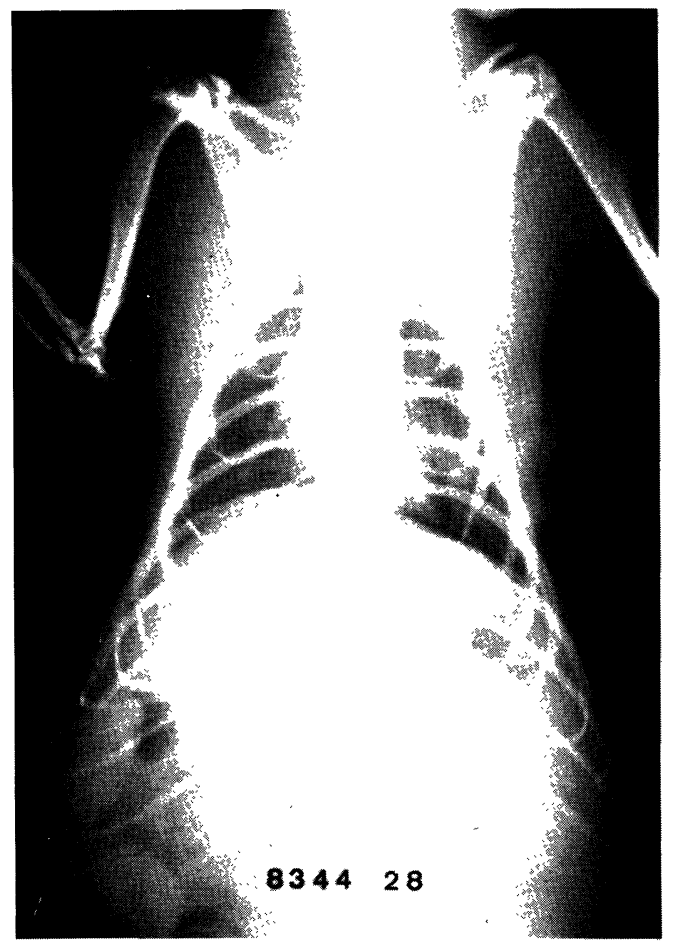

Fig. 2. A chest $\mathrm{x}$-ray on 28th postoperative day. Grafted lung (left) is well aerated. 


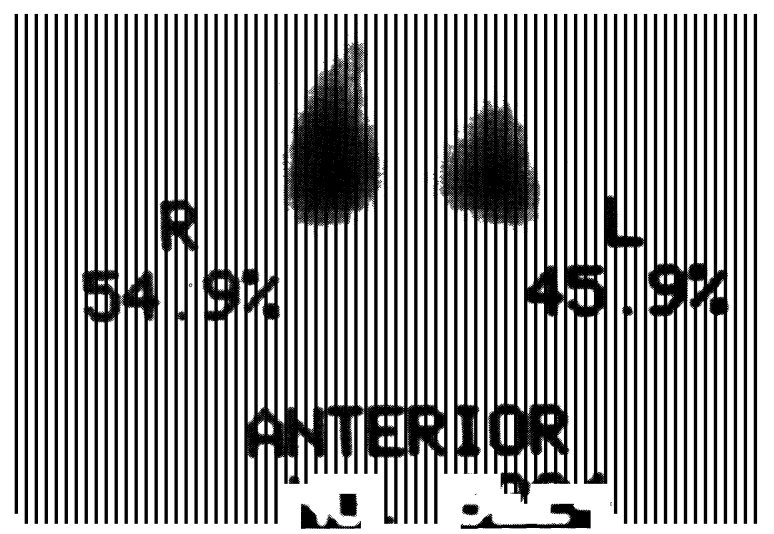

Fig. 3. A perfusion lung scan of a rat. Forty days after left lung transplantation. Perfusion ratio of the lung measured $45.9 \%$.

TABLE 1. Survival days of transplanted rats

\begin{tabular}{|c|c|c|c|c|c|c|c|c|}
\hline Group & $n$ & & & & urviva & days) & & \\
\hline W & 8 & $9^{*}$ & $15^{*}$ & (50) & (55) & $66^{*}$ & $218 \dagger$ & $350<350<$ \\
\hline $\mathrm{F}$ & 7 & $7 \ddagger$ & (28) & $(31)$ & (32) & (33) & $(42)$ & (76) \\
\hline
\end{tabular}

Cause of death

* during examination; $\dagger$ pulmonary infection

$\ddagger$ pulmonary vein thrombosis; ( ) sacrificed

TABLE 2. Perfusion ratio and chest $x$-ray findings in transplants

\begin{tabular}{ccccc}
\hline Group & No. & $\begin{array}{c}\text { Postop. } \\
\text { days }\end{array}$ & $\begin{array}{c}\text { Transplant perfusion } \\
\text { ratio }\end{array}$ & $\begin{array}{c}\text { Chest x-ray } \\
\text { film }\end{array}$ \\
\hline \multirow{4}{*}{ W } & 8212 & 47 & 18.6 & + \\
& 8223 & 49 & 24.3 & \pm \\
& 8224 & 40 & 45.1 & + \\
& 8225 & 39 & 32.1 & + \\
\hline \multirow{6}{*}{ F } & 8226 & 30 & 16.8 & + \\
& 8328 & 74 & 21.1 & + \\
& 8341 & 26 & 31.9 & + \\
& 8342 & 24 & 17.8 & + \\
\hline
\end{tabular}

+ , total left lung aerated; \pm , two-thirds of left lung aerated. 
Transplants of 12 survivals appeared grossly normal at autopsy. Autopsy disclosed pulmonary congestion due to pulmonary vein thrombosis in one dead rat in group $\mathrm{F}$, and two dead rats in group $\mathrm{W}$ had pulmonary atelectasis and infections. In 12 survivals, the anastomosed pulmonary vessels and bronchus were patent. Although mild mononuclear cell infiltration and slight thickening of the alveolar septum were occasionally encountered in the grafted tissues by microscopic examination, alveolar structures were well preserved and there was no indication of graft rejection at the sites of anastomosis.

\section{Discussion}

Asimacopoulos was the first to report the orthotopic transplantation of the rat lung, although the survival rate was less than 50\% in their hands (Asimacopoulos et al. 1971). Subsequently, Klaas W. Marck reported the lung transplantation in rats by complete anastomosis of hilar structures with a better survival rate (Marck and Wildevuur 1982). They performed the anastomosis of pulmonary vessels by continuous suture with two stay suture and that of the bronchus by interrupted suture in Wistar rats weighing 250-300 g, and it took 200-300 min (mean $240 \mathrm{~min}$ ) being ischemia time $52-149 \mathrm{~min}$ (mean $87 \mathrm{~min}$ ). We used younger rats weighing 160-250 g simply because anastomosis of hilar structures was easier in younger rats in the absence of bulky fat tissue commonly present in older rats weighing more than $250 \mathrm{~g}$. Application of continuous suture apparently contributed to higher survival rate in group F. It consumed less time and the ischemia time was subsequently shortened.

The long term follow-up by perfusion lung scan revealed that the perfusion ratio of the grafted lung in both group $\mathrm{W}$ and $\mathrm{F}$ was much less than that of normal controls. The values obtained in the present study, however, were comparable with those of the lung allotransplantation in dogs (Suzuki et al. 1969) and that reported by Marck et al. (1982).

We propose the use of this model with continuous suture as a suitable model for the study of the lung transplantation since application of the continuous suture resulted in substantial reduction of operation time and ischemia time as well without noticeable obstruction of hilar structures. The results of long term follow-up by perfusion lung scan were also satisfactory.

\section{References}

1) Asimacopoulos, P.J., Molokhia, F.A.S., Pegg, C.A.S. \& Norman, J.C. (1971) Lung transplantation in the rat. Transplant. Proc., 3, 583-585.

2) Marck, K.W. \& Wildevuur, C.R.H. (1982) Lung transplantation in the rat: I. Technique and survival. Ann. thorac. Surg., 34, 71-80.

3) Marck, K.W., Piers, D.A. \& Wildevuur, C.R.H. (1982) Lung transplantation in the rat: II. Lung perfusion scintigraphy in normal and left lung-transplanted rats. Ann. thorac. Surg., 34, 81-88.

4) Suzuki, C., Nakada, T., Moriyama, R., Kawakami, M. \& Fujimura, S. (1969) Func- 
tional studies of the transplanted lung. $J$. thorac. cardiovasc. Surg., 57, 562-576. 